OPEN ACCESS

Edited by:

Maurizio Acampa,

Siena University Hospital, Italy

Reviewed by:

Joanna Dabrowska,

Rosalind Franklin University

of Medicine and Science,

United States

Muriel Larauche,

University of California, Los Angeles,

United States

Alvaro Munoz,

Universidad de Guadalajara, Mexico

*Correspondence:

Eduardo Mazuco Cafarchio eduardo.cafarchio@gmail.com

Monica A. Sato

monica.akemi.sato@gmail.com

Specialty section:

This article was submitted to

Autonomic Neuroscience,

a section of the journal

Frontiers in Physiology

Received: 19 November 2019

Accepted: 30 March 2020

Published: 06 May 2020

Citation:

Cafarchio EM, da Silva LA,

Auresco LC, Rodart IF, de Souza JS,

Antonio $B B$, Venancio $D P$,

Maifrino LBM, Maciel RMB,

Giannocco G, Aronsson P and

Sato MA (2020) Oxytocin Reduces

Intravesical Pressure in Anesthetized

Female Rats: Action on Oxytocin

Receptors of the Urinary Bladder.

Front. Physiol. 11:382.

doi: 10.3389/fphys.2020.00382

\title{
Oxytocin Reduces Intravesical Pressure in Anesthetized Female Rats: Action on Oxytocin Receptors of the Urinary Bladder
}

\begin{abstract}
Eduardo M. Cafarchio'1*, Luiz A. da Silva', Luciana C. Auresco', Itatiana F. Rodart², Janaina S. de Souza ${ }^{3}$, Bruno B. Antonio', Daniel P. Venancio', Laura B. M. Maifrino", Rui M. B. Maciel ${ }^{3}$, Gisele Giannocco ${ }^{3}$, Patrik Aronsson ${ }^{5}$ and Monica A. Sato ${ }^{1 *}$
\end{abstract}

'Department Morphology and Physiology, Faculdade de Medicina do ABC, Centro Universitário Saúde ABC, Santo André, Brazil, ${ }^{2}$ Department Collective Health, Human Reproduction and Genetics Center, Faculdade de Medicina do ABC, Centro Universitário Saúde ABC, Santo André, Brazil, ${ }^{3}$ Department Medicine, Federal University of São Paulo, São Paulo, Brazil, ${ }^{4}$ Laboratory of Histomophometry, Universidade São Judas Tadeu, São Paulo, Brazil, ${ }^{5}$ Department Pharmacology, Institute of Neuroscience and Physiology, Sahlgrenska Academy, University of Gothenburg, Gothenburg, Sweden

Urinary bladder dysfunction affects several people worldwide and shows higher prevalence in women. Micturition is dependent on the Barrington's nucleus, pontine urine storage center and periaqueductal gray matter, but other brain stem areas are involved in the bladder regulation. Neurons in the medulla oblongata send projections to hypothalamic nuclei as the supraoptic nucleus, which synthetizes oxytocin and in its turn, this peptide is released in the circulation. We investigated the effects of intravenous injection of oxytocin (OT) on the urinary bladder in sham and ovariectomized rats. We also evaluated the topical (in situ) action of OT on intravesical pressure (IP) as well as the existence of oxytocin receptors in the urinary bladder. In sham female Wistar rats, anesthetized with isoflurane, intravenous infusion of OT (10 ng/ $/ \mathrm{kg})$ significantly decreased the IP $(-47.5 \pm 1.2 \%)$ compared to saline $(3.4 \pm 0.7 \%)$. Similar effect in IP was observed in ovariectomized rats after i.v. OT (-41.9 $\pm 2.9 \%)$ compared to saline $(0.5 \pm 0.6 \%)$. Topical administration (in situ) of $0.1 \mathrm{~mL}$ of OT $(1.0 \mathrm{ng} / \mathrm{mL})$ significantly reduced the IP $(22.3 .0 \pm 0.6 \%)$ compared to saline $(0.9 \pm 0.7 \%)$. We also found by qPCR that the gene expression of oxytocin receptor is present in this tissue. Blockade of oxytocin receptors significantly attenuated the reduction in IP evoked by oxytocin i.v. or in situ. Therefore, the findings suggest that (1) intravenous oxytocin decreases IP due to bladder relaxation and (2) OT has local bladder effect, binding directly in receptors located in the bladder.

Keywords: intravesical pressure, urinary bladder, oxytocin, receptors, vasopressin (ADH)

\section{INTRODUCTION}

The bladder dysfunctions cause social and mental discomfort and affect the well-being due to the difficulty of performing several normal activities in daily life. Dysfunctions of the lower urinary tract are frequent complaints, accounting for up to $40 \%$ in ambulatories of nephrology and urology (Bakker et al., 2002; Kajiwara et al., 2004; Hashim et al., 2009; Sureshkumar et al., 2009). The urinary 
bladder disorders, particularly urinary incontinence symptoms show higher prevalence in women (Aoki et al., 2017).

The detrusor of the urinary bladder is composed of smooth muscle with gap junctions between its cells (Steers, 1998). The detrusor and the internal sphincter are innervated by the autonomic nervous system. Urine storage and micturition depend on coordination between two functional units: the urinary bladder and the striated musculature of the urethral sphincter (de Groat, 1998; Andersson and Hedlund, 2002).

Albeit complex, it is known that the central control of micturition is dependent on Barrington's nucleus (pontine micturition center), pontine urine storage center (PUSC) and periaqueductal gray matter (PAG) (de Groat, 1998). Brain stem areas such as the nucleus of the solitary tract (NTS), caudal ventrolateral medulla (CVLM), and rostral ventrolateral medulla (RVLM) are best known for their involvement in cardiovascular regulation. Nevertheless, it has also been shown that they can elicit changes in pelvic nerve activity (Chen and Chai, 2002; Cafarchio et al., 2018). Previous studies have demonstrated that the NTS and RLVM have projections for hypothalamic nuclei, which contains the cell bodies of neurons responsible for the production of vasopressin and oxytocin (OT). Those peptides are transported through the axons and released by the neurophypophysis in the circulation (Ross et al., 1984; Romine and Anderson, 1985). While those areas can elicit vasopressin release by cholinergic activation of medullary neurons, activation or (Cafarchio et al., 2016) blockade of cholinergic receptors in the medulla does not release OT in the plasma (Cafarchio et al., 2016). On the other hand, OT neurons in the supraoptic nucleus receive noradrenergic projections from the $\mathrm{A} 1$ and $\mathrm{A} 2$ cell groups in the medulla oblongata (Onaka et al., 2001; Zhu and Onaka, 2002). The A2 noradrenergic neurons seem to be involved in the activation of OT neurons after conditioned fear stimuli (Zhu and Onaka, 2002), whereas A1 noradrenergic neurons may mediate OT release after noxious stimuli (Onaka et al., 2001).

Oxytocin is a nonapeptide synthesized in the paraventricular nucleus (PVN) and supraoptic nucleus (SON), which are both hypothalamic nuclei. Magnocellular neurons located in the PVN and SON are responsible for the largest part of the OT release but a small percentage of OT is produced by parvocellular neurons of the PVN (Gutkowska et al., 2000a,b; Stern, 2015). The hormone is transported by carrier proteins from the magnocellular neurons of the SON and PVN and parvocellular neurons of the PVN to the neurohypophysis, where the neuropeptide is stored and released into the bloodstream (Swanson and Sawchenko, 1980; Johnson and Thunhorst, 1997; Freeman and Young, 2016). Oxytocin is mostly known for its peripheral action in milk ejection and parturition (Romine and Anderson, 1985; Onaka et al., 2001), however studies on isolated preparations have shown that oxytocin elicits contraction of the rabbit detrusor muscle (Romine and Anderson, 1985). Oxytocin also has a protective role during ischemia and reperfusion injury in the rat urinary bladder (Du Vigneaud, 1954). Nevertheless, to the best of our knowledge the existence of oxytocin receptors has not been demonstrated in the urinary bladder.

The ovarian hormone estrogen is an important inducer of OT receptors in several tissues (Bale et al., 1995; Zigon, 2013;
Narita et al., 2016) and exerts physiological functions, such as in parturition and milk ejection, through the release of OT (Zingg et al., 1995; Zhou and Forsling, 2000; Narita and Ichimaru, 2014). Evidence also indicates that the effects of OT on the magnitude of diuresis and natriuresis are dependent on the phase of the estrous cycle (Zhou and Forsling, 2000).

No previous study has described the existence neither functionality of OT receptors in the rat urinary bladder nor the effects of systemic and topical OT administration on the bladder in anesthetized rats. Thereby, this study focused to investigate the effects of intravenous injection of OT on the urinary bladder in intact and ovariectomized female rats. We also evaluated the topical (in situ) action of OT on intravesical pressure (IP) as well as the expression of oxytocin receptors in the urinary bladder.

\section{MATERIALS AND METHODS}

\section{Animals}

Thirty-two female Wistar rats $(\sim 250-300$ g, 14-16 weeks-old) provided by the Animal Facility of the Faculdade de Medicina do $A B C$ were used. The animals were housed in groups of 3 rats/cage, except when they were submitted to ovariectomy or sham surgery, in which they were maintained in individual plastic cages until healing. Animals had access to standard chow pellets and tap water ad libitum, and were maintained in an air conditioned room $\left(20-24^{\circ} \mathrm{C}\right)$ with a $12: 12 \mathrm{~h}$ light-dark cycle. The humidity of the animal room was set at $\sim 70 \%$. All procedures were performed in accordance with the National Institutes of Health (NIH) Guide for the Care and Use of Laboratory Animals, and were approved by the Animal Ethics Committee of the Faculdade de Medicina do ABC (protocol number 007/2011).

\section{Ovariectomy Surgery}

The group of ovariectomized rats was anesthetized with ketamine (50 mg/kg, i.p., Dopalen ${ }^{\circledR}$, Ceva Saude Animal, Paulinia, Brazil) and xylazine $\left(10 \mathrm{mg} / \mathrm{kg}\right.$, i.m, Anasedan ${ }^{\circledR}$, Ceva Saude Animal, Paulinia, Brazil). After abdominal trichotomy, an incision of about $2 \mathrm{~cm}$ was made in the lateral flank until reaching the abdominal cavity. The ovaries were exposed, tied and completely harvested bilaterally and the incisions were subsequently suture closed. At the end of surgery, the rats received a single dose of Veterinary Pentabiotic for Small Animals (2,000 U/mL, i.m., FortDodge, Campinas, Brazil) as a prophylactic procedure and tramadol (10 mg/kg, i.m., Tramal ${ }^{\circledR}$, Pfizer, Sao Paulo, Brazil) at the end of surgery and every $12 \mathrm{~h}$ in the immediate post-operative period (1 day after surgery). The animals recovered from surgery for 21 days in order to reduce the circulating estrogen levels, in accordance to earlier studies (Deer and Stallone, 2016). Sham rats underwent the same surgical procedures, but the ovaries were not removed.

\section{Cannulation of the Urinary Bladder}

The rats were anesthetized with $2 \%$ isoflurane (BioChimico, Penedo, Itatiaia, Brazil) in $100 \% \mathrm{O}_{2}$ and subjected to a partial laparotomy and a small incision in the bladder wall was performed for insertion of a polyethylene tubing (PE-50 
connected to PE-10, Clay Adams, NJ, United States) filled with saline at the appex of the bladder. A small drop of tissue glue was used to fix the catheter on the bladder wall for IP recordings in a data acquisition system (PowerLab 16 SP, AD Instruments, Castle Hill, AU, United States). The abdominal cavity was covered with gaze dressing humidified with saline. The urethra outlet was not submitted to ligature in order to permit the bladder voiding if necessary. A baseline IP value was set at $\sim 8-10 \mathrm{mmHg}$ by saline infusion or urine withdrawal through the catheter inserted into the urinary bladder.

\section{Cannulation of the Femoral Artery and Vein}

The rats anesthetized with $2 \%$ isoflurane (BioChimico, Penedo, Itatiaia, RJ, Brazil) in $100 \% \mathrm{O}_{2}$ were subjected to cannulation of the femoral artery and vein by inserting a polyethylene tubing (PE-50 connected to PE-10, Clay Adams, NJ, United States) for pulsatile arterial pressure (PAP), mean arterial pressure (MAP) and heart rate (HR) recordings in the data acquisition system (PowerLab 16 SP, AD Instruments, Castle Hill, AU, United States), and for drug administration, respectively.

\section{RNA Isolation and Quantitative Real-Time RT-PCR}

Total RNA was isolated from frozen urinary bladder (weighing $\sim 100 \mathrm{mg}$ ) with TRIzol Reagent ${ }^{\circledR}$ (Life Technologies Corporation, Carlsbad, CA, United States) according to the manufacturer's protocol. RNA integrity was checked by agarose gel electrophoresis, and RNA purity reached the following criteria: A260/280 $\geq 1.8$. The extracted total RNA concentration was measured using a Nanodrop spectrophotometer (ND-1000) (Bio-Rad, United States), and $1 \mu \mathrm{g}$ of total RNA was subjected to reverse transcription reaction. Complementary DNA (cDNA) synthesis was generated using ImProm-II ${ }^{\mathrm{TM}}$ Reverse Transcription System (Promega, Madison, WC) according to the manufacturer's protocol. Quantitative real-time PCR (qPCR) was carried out using $2 \mu \mathrm{L}$ of $\mathrm{CDNA}$ and the $\mathrm{SYBR}^{\mathrm{TM}}$ Green PCR Master Mix (Thermo Fisher Scientific, Waltham, MA, United States) in the ABI Prism 7500 Sequence Detection System (Applied Biosystems, Foster City, CA, United States) to amplify specific primers sequences for oxytocin receptors. The forward and reverse primers sequences for rats were, respectively:
OT receptor: (forward)- 5'-CATGCTGCTGGCTAGCC TTA-3'
(reverse)- 5'-CAAAGCAGGCTACGCAAC $\mathrm{TC}-3^{\prime}$
Cyclophilin A: (forward)- $5^{\prime}$-CCCACCGTGTTCTTCGA CAT- $3^{\prime}$;
(reverse)- 5'-CTGTCTTTGGAACTTTGTC TGCAA- $3^{\prime}$

Cyclophilin A was used as internal control (housekeeping gene). The procedure consisted of an initial step of $10 \mathrm{~min}$ at $95^{\circ} \mathrm{C}$ followed by 45 cycles of $20 \mathrm{~s}$ each at $95^{\circ} \mathrm{C}, 20 \mathrm{~s}$ at $58^{\circ} \mathrm{C}$, and $20 \mathrm{~s}$ at $72^{\circ} \mathrm{C}$. Gene expression was determined by CT, and all values were expressed using cyclophilin A mRNA as an internal control.

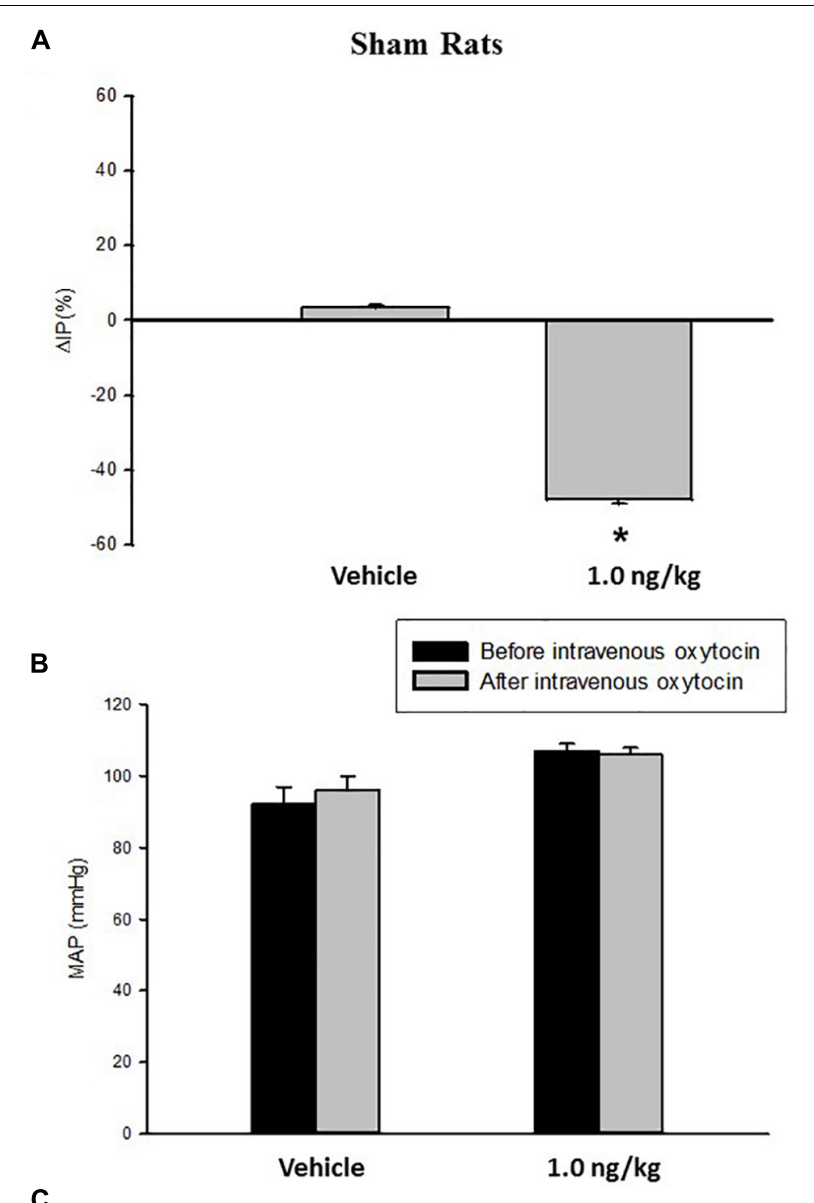

C

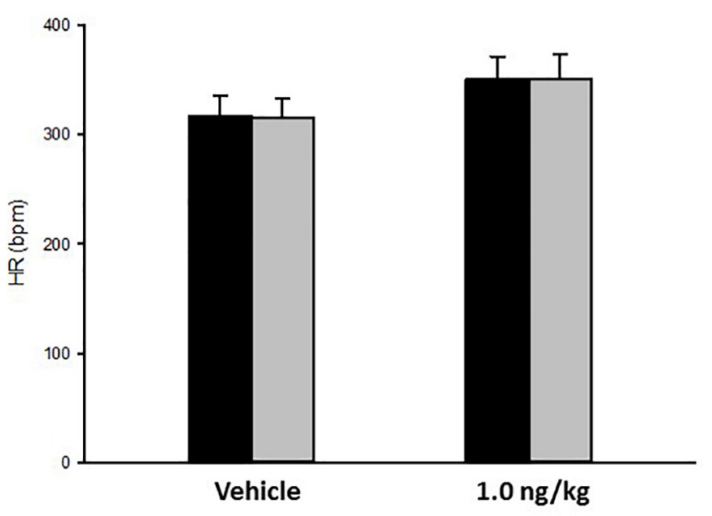

FIGURE 1 | Percent change in intravesical pressure $(\mathbf{A}, \% \Delta \mathrm{IP})$ after intravenous injection of saline (vehicle) or oxytocin dose (1.0 ng/kg of b.w.) in sham animals. Mean arterial pressure $(\mathbf{B}, \mathrm{MAP}, \mathrm{mmHg})$ and heart rate $(\mathbf{C}, \mathrm{HR}$, bpm) at baseline and after intravenous injection of saline (vehicle) or oxytocin dose (1.0 ng/kg of b.w.) in sham animals, ${ }^{*} p<0.05$ vs. saline $(N=7)$.

\section{Experimental Protocols}

Intravenous Injection of Oxytocin on Urinary Bladder and Cardiovascular Parameters in Sham and Ovariectomized Rats

Sham (control) and ovariectomized rats were anesthetized with isoflurane and submitted to catheterization of the femoral artery 
A

Ovariectomized rats

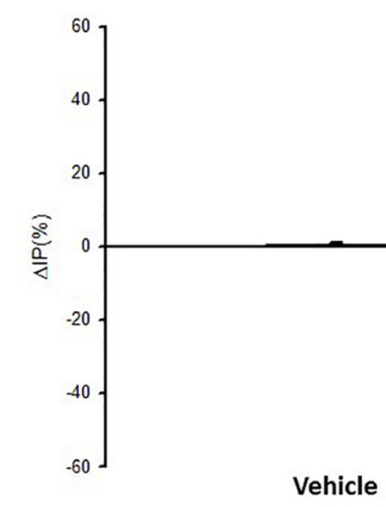

B

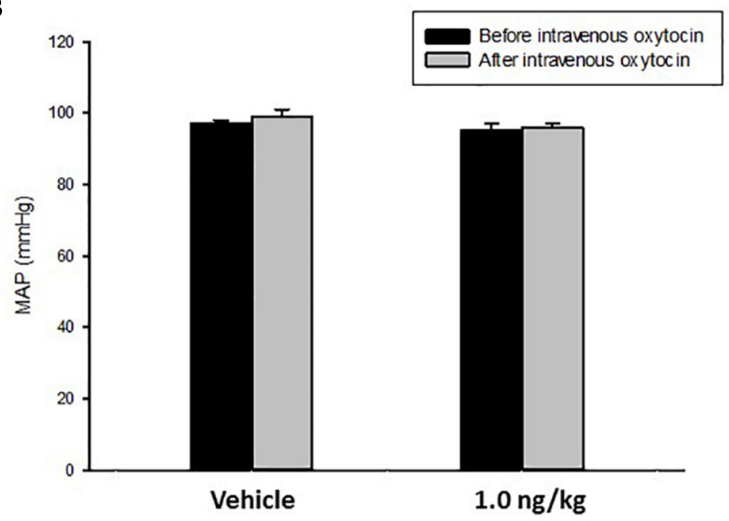

C

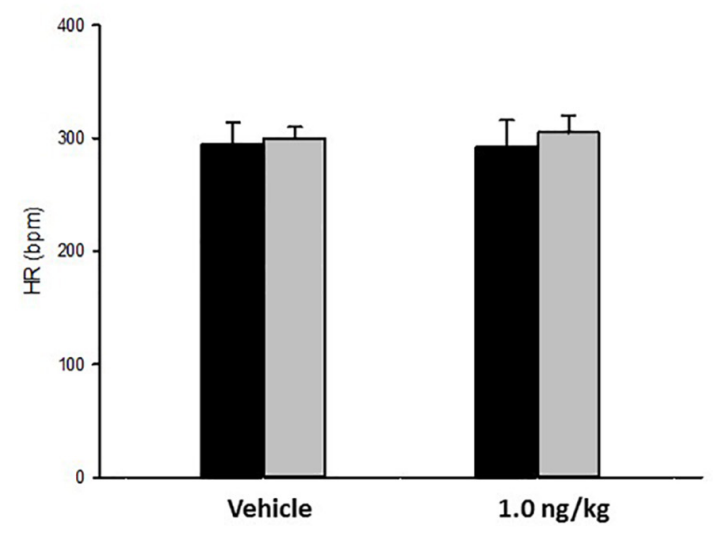

FIGURE 2 | Percent change in intravesical pressure (A, \% $\Delta \mathrm{IP})$ after intravenous injection of saline (vehicle) or oxytocin dose (1.0 ng/kg of b.w.). Mean arterial pressure (B, MAP, $\mathrm{mmHg}$ ) and heart rate (C, HR, bpm) at baseline and after intravenous injection of saline (vehicle) or oxytocin dose (1.0 $\mathrm{ng} / \mathrm{kg}$ of b.w.) in ovariectomized animals ${ }^{*} p<0.05$ vs. saline $(N=6)$.

and vein, and cannulation of the urinary bladder as described above. After the baseline recordings of PAP, MAP, HR, and IP for $15 \mathrm{~min}$, saline $(1 \mathrm{~mL} / \mathrm{kg}$, vehicle) or oxytocin (oxytocin acetate salt hydrate, Sigma Aldrich cat\#O6379, lot\# EC 200-048-4, St. Louis, MO, United States) at $1.0 \mathrm{ng} / \mathrm{kg}$ of b.w. was administrated for 5 min using an infusion pump (Insight Ltda, Ribeirão Preto, SP, Brazil). Saline or oxytocin were randomly injected in the animals. The oxytocin solution was prepared in a concentration of $1.0 \mathrm{ng} / \mathrm{mL}$. All the parameters were recorded during the infusion and for additional $30 \mathrm{~min}$. Each infusion was carried out only after the parameters have recovered to baseline levels. At the end of the experiments, rats were euthanized with an overdose of sodium thiopental (70 mg/kg, i.v.).

\section{Effects of in situ Oxytocin Administration on the Urinary Bladder and Cardiovascular Parameters in Sham Rats}

Under isoflurane anesthesia, rats underwent to the catheterization of the femoral artery and cannulation of the urinary bladder. After the baseline recording of PAP, MAP, HR, and IP for $15 \mathrm{~min}, 0.1 \mathrm{~mL}$ of saline or oxytocin (oxytocin acetate salt hydrate, Sigma Aldrich cat\#O6379, lot\# EC 200-048-4, St. Louis, MO, United States) (1.0 ng/rat) was dropped on the outside of the urinary bladder, in order to evaluate the topical (in situ) action. All animals received both saline and oxytocin topically on the urinary bladder and the parameters were recorded for $30 \mathrm{~min}$. Each in situ administration was carried out only after the parameters had recovered to baseline levels. At the end of the experiments, rats were euthanized with an overdose of sodium thiopental (70 $\mathrm{mg} / \mathrm{kg}$, i.v.).

\section{Intravenous and in situ Oxytocin Effects on Urinary Bladder and Cardiovascular Parameters Upon Blockade of Oxytocin Receptors in Sham Rats}

Sham (control) rats were anesthetized with isoflurane and submitted to catheterization of the femoral artery and vein, and cannulation of the urinary bladder as described above. After the baseline recordings of PAP, MAP, HR, and IP for 15 min, $\beta$-Mercapto- $\beta, \beta$-cyclopentamethylenepropionyl ${ }^{1}, \mathrm{O}-\mathrm{Me}$ $\mathrm{Tyr}^{2}, \mathrm{Orn}^{8}$ ]-Oxytocin $(10 \mu \mathrm{g} / \mathrm{kg}$ of b.w, Sigma Aldrich cat\# O6887 lot\#079K1684, St. Louis, MO, United States), an oxytocin receptor antagonist, was administrated intravenously for $5 \mathrm{~min}$ using an infusion pump (Insight Ltda, Ribeirão Preto, Brazil). After $30 \mathrm{~min}$, oxytocin $1 \mathrm{ng} / \mathrm{kg}$ was injected intravenously or in situ ( $0.1 \mathrm{ng} / \mathrm{rat})$ onto the bladder surface in the animals. The oxytocin solution was prepared in a concentration of 1.0 $\mathrm{ng} / \mathrm{mL}$. All the parameters were recorded during the infusion and for additional $30 \mathrm{~min}$. At the end of the experiments, rats were euthanized with an overdose of sodium thiopental (70 mg/kg, i.v.).

\section{Gene Expression of Oxytocin Receptor on the Urinary Bladder}

In a separate group of animals $(N=6)$, which was different from those included in the functional experiments of this study, rats were deeply anesthetized with $2 \%$ isoflurane in $100 \% \mathrm{O}_{2}$ and a midline incision was performed in the abdomen and the urinary bladder was harvested and immediately frozen in liquid nitrogen. Afterward, the samples were stored in an ultrafreezer at $-80^{\circ} \mathrm{C}$ until RNA extraction. All the animals used for gene expression were intact rats. The further procedures for gene expression of oxytocin receptor in the urinary bladder were performed by qPCR, according to the procedures described in section RNA Isolation and Quantitative Real-Time RT-PCR. After the bladder 
Sham Rats

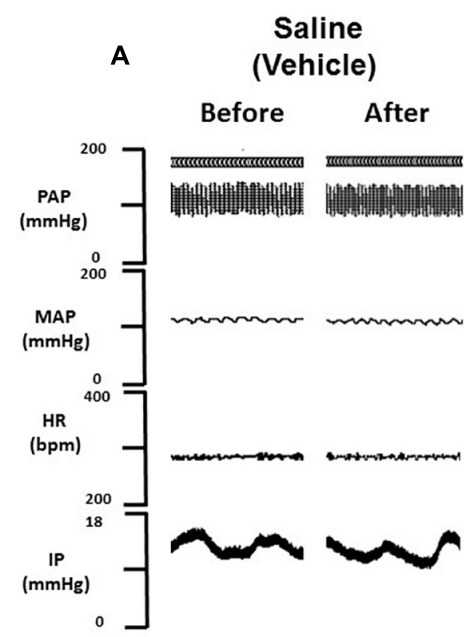

Oxytocin

$(1.0 \mathrm{ng} / \mathrm{Kg})$

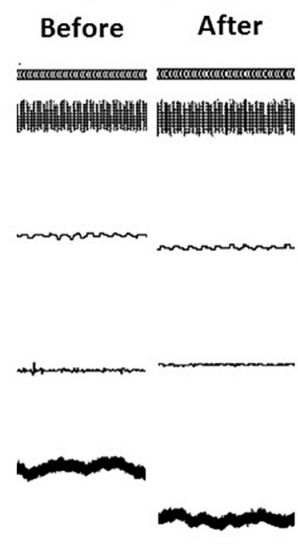

Ovariectomized Rats

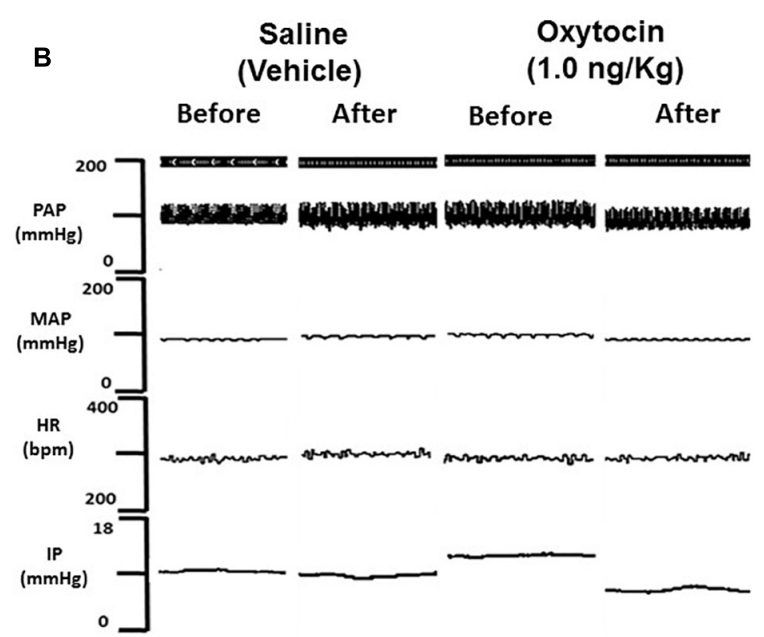

FIGURE 3 | Tracings showing pulsatile arterial pressure (PAP, mmHg), mean arterial pressure (MAP, mmHg), heart rate (HR, bpm) and intravesical pressure (IP, $\mathrm{mmHg}$ ) before and after intravenous infusion of saline (vehicle) or oxytocin $10 \mathrm{ng} / \mathrm{kg}$ in sham (A) and ovariectomized (B) rats.

was harvest, the rats were euthanized with an overdose of sodium thiopental (70 $\mathrm{mg} / \mathrm{kg}$, i.v.).

\section{Statistics}

A Komolgorov-Smirnov test for normality was used for verifying the data distribution. Once the results fit to a normal distribution, they were expressed as mean \pm S.E.M. Data were submitted to paired Student $t$-test for comparison between the baseline and the responses after i.v. or topical oxytocin intra-group, and unpaired Student $t$-test for comparison of baseline or the responses after oxytocin between sham and ovariectomized rats. Statistical analysis were conducted using the statistical software package Sigma Stat 3.5. Significance level was set at $P<0.05$.

\section{RESULTS}

\section{Effects of Intravenous Infusion of Oxytocin on Intravesical Pressure, Arterial Pressure, and Heart Rate in Sham and Ovariectomized Rats}

At baseline (before intravenous injection of oxytocin), the MAP was $92 \pm 5 \mathrm{mmHg}$, the HR was $300 \pm 14 \mathrm{bpm}$ and the IP was $11 \pm 1.0 \mathrm{mmHg}$ in sham (control) rats $(N=7)$.

Intravenous infusion of oxytocin $1.0 \mathrm{ng} / \mathrm{kg}$ in sham rats evoked a significant decrease in IP $(-47.5 \pm 1.2 \%)$ compared to saline infusion $(3.4 \pm 0.7 \%$ ) (Figures 1, 3). The onset of the response in IP occurred at $10 \mathrm{~min}$ after starting the oxytocin infusion and the peak response was achieved at $15 \mathrm{~min}$ after the onset of infusion. The fall in IP lasted for additional 5 min after achieving the peak response.

No significant changes were observed in MAP, and HR after the injection of oxytocin in sham rats (Figures 1, 3).
In ovariectomized rats, at baseline (before the intravenous injection of oxytocin) the MAP was $97 \pm 1 \mathrm{mmHg}$, the HR was $295 \pm 19 \mathrm{bpm}$ and the IP was $12 \pm 0.5 \mathrm{mmHg}(N=6)$.

Intravenous infusion of oxytocin $(1.0 \mathrm{ng} / \mathrm{kg})$ in ovariectomized rats $(N=6)$ elicited a significant reduction in IP $(-41.9 \pm 2.9 \%)$ compared to saline infusion $(0.5 \pm 0.6 \%)$ (Figures 2, 3). Similarly to the sham (control) group, the onset of the response was $10 \mathrm{~min}$ after the beginning of oxytocin infusion and the peak response was achieved at 15 min after starting the infusion of oxytocin. The decrease in IP lasted for additional 5 min after achieving the peak response.

No significant changes were observed in MAP and HR after the infusion of oxytocin in ovariectomized rats (Figures 2, 3).

We observed no difference in the IP and cardiovascular responses evoked by i.v. oxytocin comparing ovariectomized and sham rats.

\section{Effects of the in situ Administration of Oxytocin on the Intravesical Pressure and Cardiovascular Parameters in Sham Rats}

At the baseline (before in situ administration of oxytocin), rats showed $95 \pm 3 \mathrm{mmHg}$ of MAP, $315 \pm 22 \mathrm{bpm}$ of HR, and $8.3 \pm 1.7 \mathrm{mmHg}$ of IP $(N=7)$.

Topical administration (in situ) of oxytocin (0.1 ng/rat) elicited a significant decrease in IP $(-22.3 \pm 0.6 \%)$ compared to saline administration $(0.9 \pm 0.7 \%$; Figures 4,5$)$. The decrease in IP was observed about 5 min after oxytocin was topically dropped onto the bladder. The fall in IP lasted for additional 5 min after achieving the peak response.

No significant changes were observed in MAP and HR after the administration of oxytocin compared to saline (Figures 4, 5). 


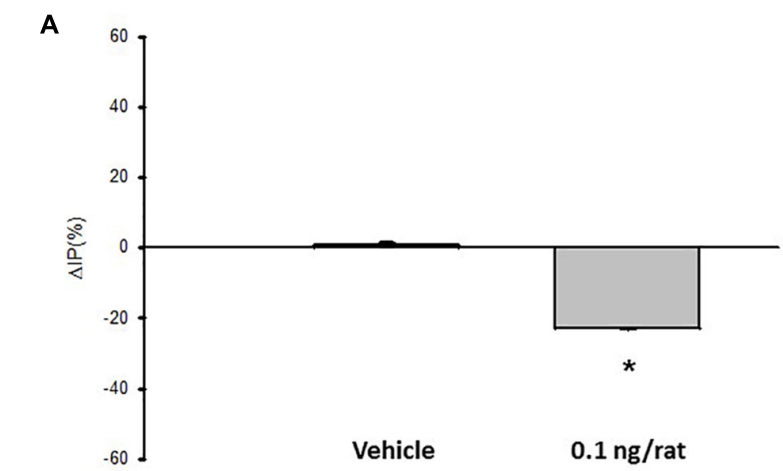

B

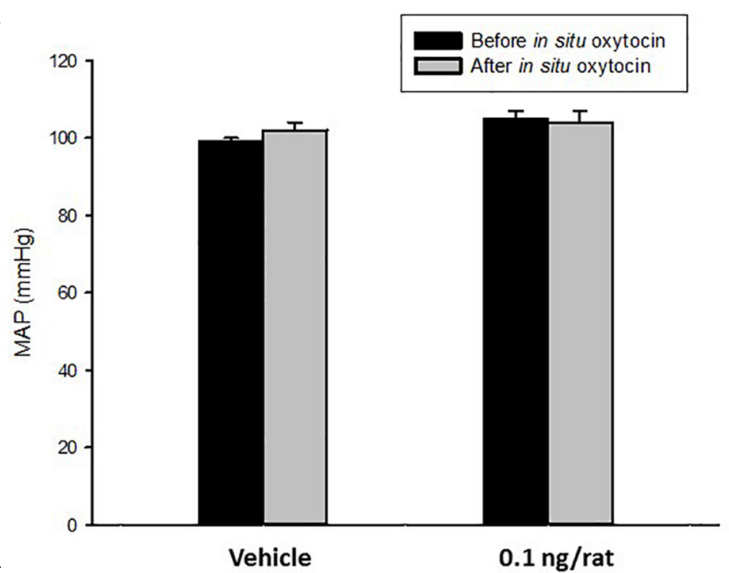

C

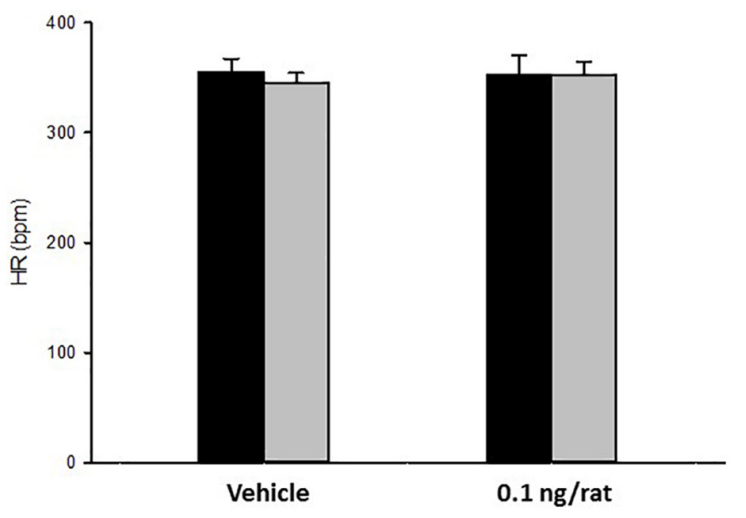

FIGURE 4 | Percent change in intravesical pressure (A,\% $\% \mathrm{IP})$ after in situ administration of $0.1 \mathrm{~mL}$ of saline (vehicle) or oxytocin $(0.1 \mathrm{ng} / \mathrm{rat})$ in sham animals $(N=7)$. Mean arterial pressure $(\mathbf{B}, \mathrm{MAP}, \mathrm{mmHg})$ and heart rate $(\mathbf{C}, \mathrm{HR}$, bpm) at baseline and after in situ administration of $0.1 \mathrm{~mL}$ of saline (vehicle) or oxytocin dose $(0.1 \mathrm{ng} / \mathrm{rat})$ in sham animals, ${ }^{*} p<0.05 \mathrm{vs}$. saline $(N=6)$.

\section{Intravenous and in situ Oxytocin Effects on Urinary Bladder and Cardiovascular Parameters Upon Blockade of Oxytocin Receptors in Sham Rats}

At the baseline (before administration of oxytocin receptor antagonist, OTra), rats of the OTra + i.v. OT group showed $104 \pm 2 \mathrm{mmHg}$ of MAP, $368 \pm 10 \mathrm{bpm}$ of $\mathrm{HR}$ and
$10.1 \pm 0.3 \mathrm{mmHg}$ of IP $(N=5)$. Thirty minutes after intravenous injection of oxytocin receptor blockade, no significant changes were observed in MAP and HR. IP showed only a small decrease to $9.1 \pm 0.2 \mathrm{mmHg}$. Intravenous injection of oxytocin after intravenous blockade of oxytocin receptors showed a significant attenuated decrease in IP $(-8.2 \pm 0.6 \%)$ compared to the i.v. oxytocin control response in sham rats $(-41.9 \pm 2.9 \%)$ shown in section Effects of Intravenous Infusion of Oxytocin on Intravesical Pressure, Arterial Pressure, and Heart Rate in Sham and Ovariectomized Rats (Figure 6).

Before administration of oxytocin receptor antagonist (OTra), rats of the OTra + in situ OT group at baseline showed $106 \pm 2 \mathrm{mmHg}$ of MAP, $358 \pm 5 \mathrm{bpm}$ of $\mathrm{HR}$ and $9.7 \pm 0.8 \mathrm{mmHg}$ of IP $(N=5)$. Thirty minutes after intravenous injection of oxytocin receptor blockade, no significant changes were observed in MAP, HR and IP $(9.7 \pm 1.1 \mathrm{mmHg})$. In situ oxytocin after intravenous blockade of oxytocin receptors also showed a significant attenuated decrease in IP $(-13.6 \pm 0.7 \%)$ compared to the i.v. oxytocin control response in sham rats $(-22.3 \pm 0.6 \%)$ shown in section Effects of the in situ Administration of Oxytocin on the Intravesical Pressure and Cardiovascular Parameters in Sham Rats (Figure 7).

\section{Gene Expression of Oxytocin Receptor in the Urinary Bladder}

The results of the gene expression by qPCR in the urinary bladder demonstrated that the oxytocin receptor as well as the housekeeping gene cyclophilin A is present in this tissue $(N=6)$. The CT values for the oxytocin receptor and cyclophilin A are shown in Figure 8.

\section{DISCUSSION}

Our study showed, to the best of our knowledge, for the first time that intravenous administration of oxytocin decreases the IP in anesthetized rats. In sham (control) rats (without ovariectomy), oxytocin did not change any of the cardiovascular parameters studied, suggesting that the reduction in IP is not dependent on filtration pressure changes in the kidneys. Thus, it seems likely that the decrease in IP is independent of any reduction in urinary volume. There is no previous evidence in the literature of oxytocin being a modulator of urinary bladder function. In the current study, intravenous oxytocin elicited an opposite response to that previously shown for i.v. vasopressin (Cafarchio et al., 2018), although in similar concentration (1 ng/mL/kg). Vasopressin increased the contractility of urinary bladder muscle in rabbits, humans and rats at in vitro studies (Crankshaw, 1989; Holmquist et al., 1991; Dehpour et al., 1997). In anesthetized female rats, intravenous vasopressin increased the IP in a dose-dependent manner, and the increases were significantly attenuated by blockade of V1a and V2 receptors (Cafarchio et al., 2018). All subtypes of vasopressin receptors (V1a, V1b, and V2) were also found by gene and protein expression in the detrusor muscle (Cafarchio et al., 2018).

Indeed, at least in female rats, oxytocin and vasopressin can bind to their specific receptors and underpin the findings of the 


\section{In situ}

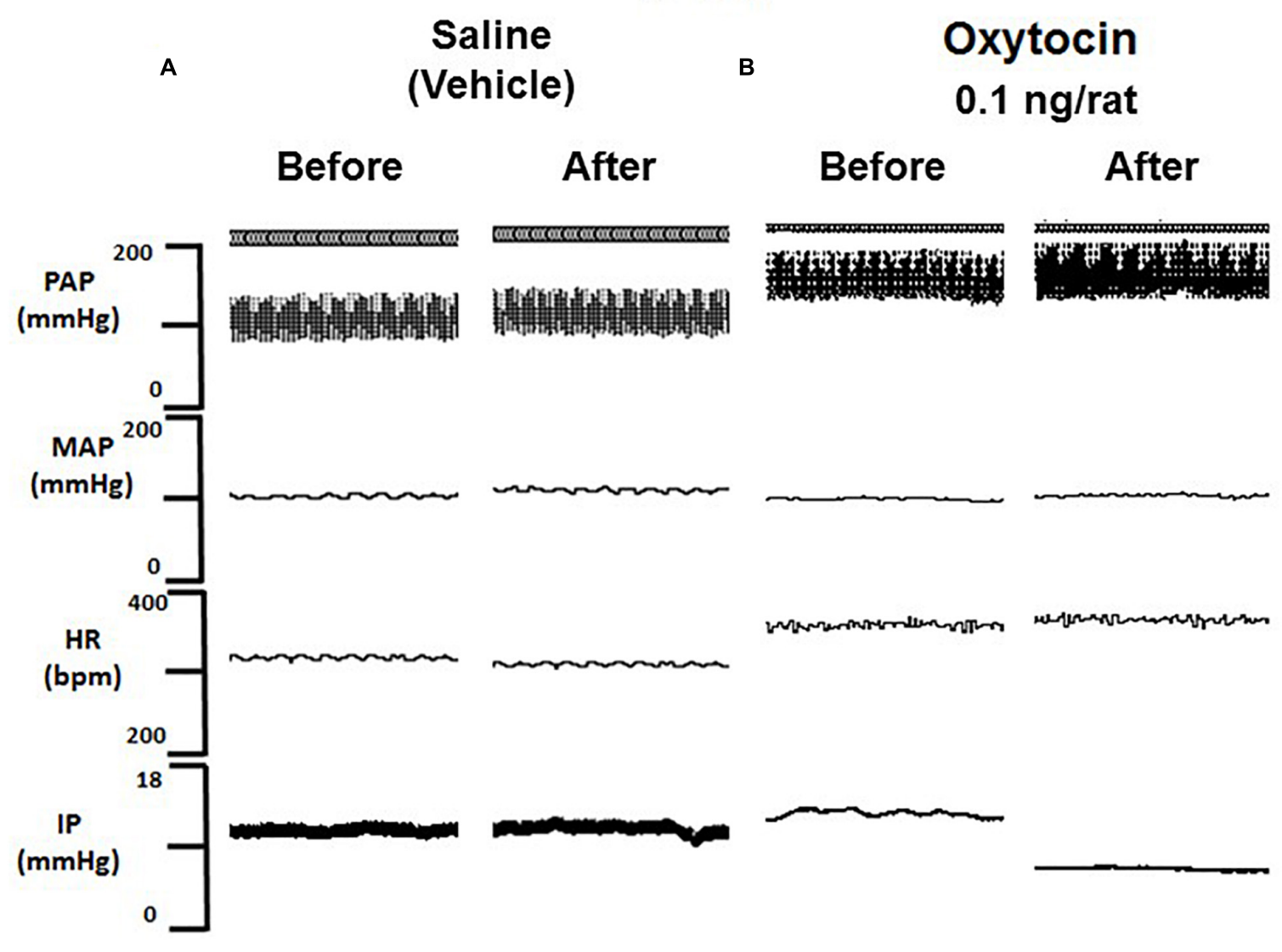

FIGURE 5 | Tracing showing pulsatile arterial pressure (PAP, mmHg), mean arterial pressure (MAP, mmHg), heart rate (HR, bpm) and intravesical pressure (IP, mmHg) before and after saline (A) or oxytocin $0.1 \mathrm{ng} / \mathrm{rat}$ (B) in situ administration on the outside of the urinary bladder in sham animals.

current study demonstrating that oxytocin can act in specific receptors in the detrusor muscle to decrease IP.

In vitro studies of isolated rabbit bladders have shown that, in contrast to the current study, oxytocin at higher doses increased the contractility of the detrusor muscle (Romine and Anderson, 1985; Pandita et al., 1998). This effect could be explained by the fact that in high doses oxytocin, due to its molecular similarity to vasopressin, can unspecifically bind to, and activate, vasopressin receptors, increasing the urinary bladder contraction in rabbits, humans and rats as shown earlier in isolated preparations (Crankshaw, 1989; Holmquist et al., 1991; Dehpour et al., 1997). Our data showed that the oxytocin receptor gene is present in the urinary bladder, suggesting that oxytocin can decrease the IP through binding in its own receptor in the bladder.

In the current study, we have described the effects of only one dose $(1 \mathrm{ng} / \mathrm{kg})$ of oxytocin and we did not include higher doses of oxytocin in order to avoid non-selective actions of oxytocin on other types of receptors as the vasopressin receptors.

Earlier studies of Petty et al. (1985) have shown that intravenous injection of oxytocin (10 ug) decreased mean arterial pressure and heart rate in conscious male rats, however, oxytocin at lower doses (100 pg and $10 \mathrm{ng}$ ) evoked no changes in the cardiovascular parameters. In the present study, we have used $1 \mathrm{ng} / \mathrm{kg}$ intravenously. Considering that the animals were weighing $\sim 250 \mathrm{~g}$, each rat has received $\sim 0.25 \mathrm{ng}$ (or $250 \mathrm{pg}$ or $0.00025 \mu \mathrm{g}$ ) of oxytocin, which were close to the doses that elicited no changes in the cardiovascular parameters as shown in the study of Petty et al. (1985). Therefore, our findings are consistent with previous findings (Petty et al., 1985) despite our experiments have been carried out in anesthetized female rats.

Although it has previously been shown that estrogen is an important inducer of oxytocin receptors in several tissues (Zingg et al., 1995; Zhou and Forsling, 2000; Narita and Ichimaru, 2014; Narita et al., 2016), the current study does not show any difference in the change of IP evoked by oxytocin in control and ovariectomized rats. Because of that, topical administration of oxytocin onto the urinary bladder of ovariectomized rats was not performed. Plasma estrogen was not measured in the present study, which is a limitation of the present study, nevertheless, it would be expected that the rats were at least in a hypoestrogenism condition after 21 days as it has been shown in earlier studies (Deer and Stallone, 2016). 


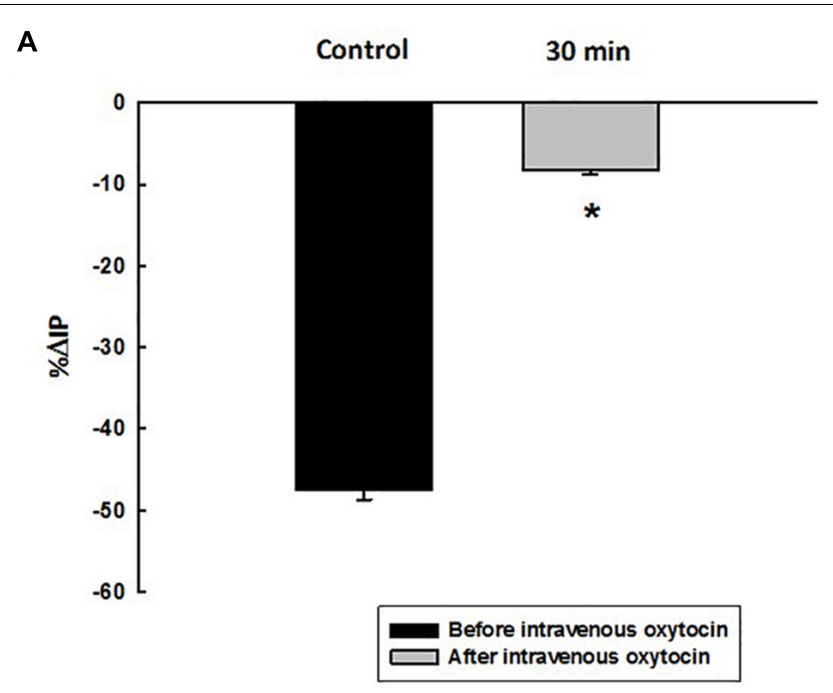

B

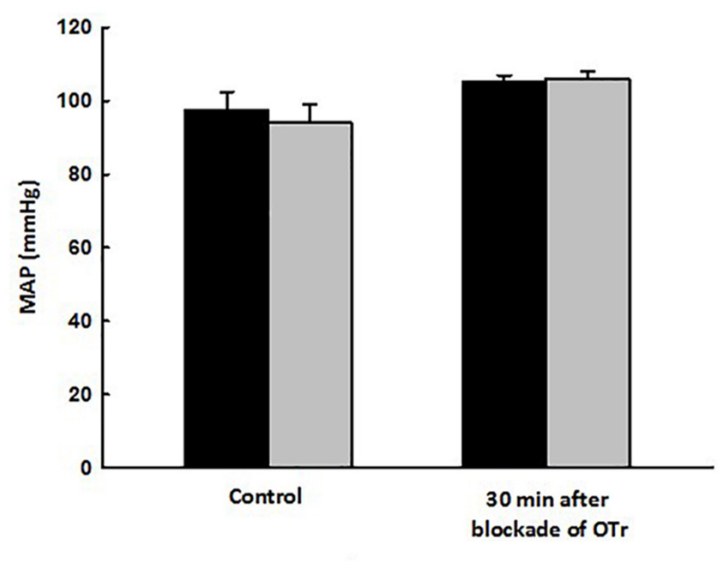

C

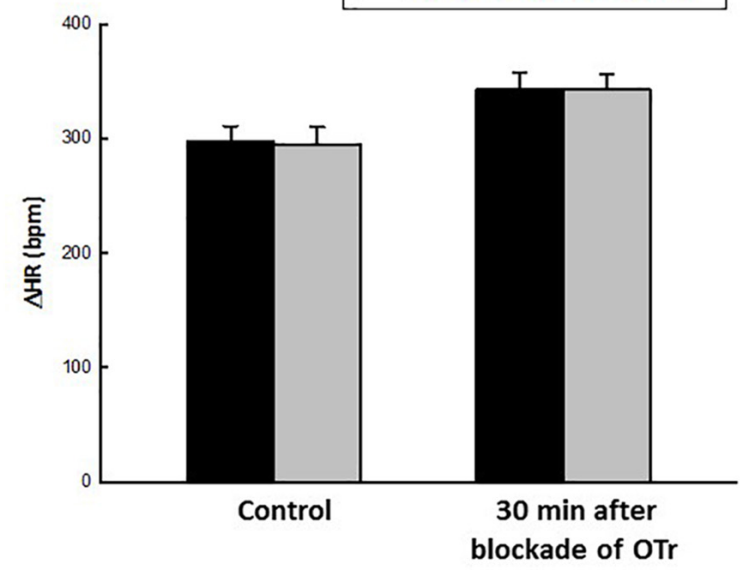

FIGURE 6 | Percent change in intravesical pressure (A, \% $\Delta \mathrm{IP})$ evoked by intravenous injection of oxytocin dose (1.0 ng/kg of b.W., control response) and at $30 \mathrm{~min}$ after blockade of oxytocin receptors (OTr) $(10 \mathrm{ug} / \mathrm{kg}$, i.v. $)$ in intact rats. Mean arterial pressure (B, MAP, $\mathrm{mmHg}$ ) and heart rate $(\mathbf{C}, \mathrm{HR}$, $\mathrm{bpm})$ at baseline and after intravenous injection of oxytocin dose $(1.0 \mathrm{ng} / \mathrm{kg}$ of b.w., control response) and also at $30 \mathrm{~min}$ after blockade of oxytocin receptors (10 ug/ $/ \mathrm{kg}$, i.v.) in sham rats, ${ }^{*} p<0.05$ vs. control $(N=5)$.

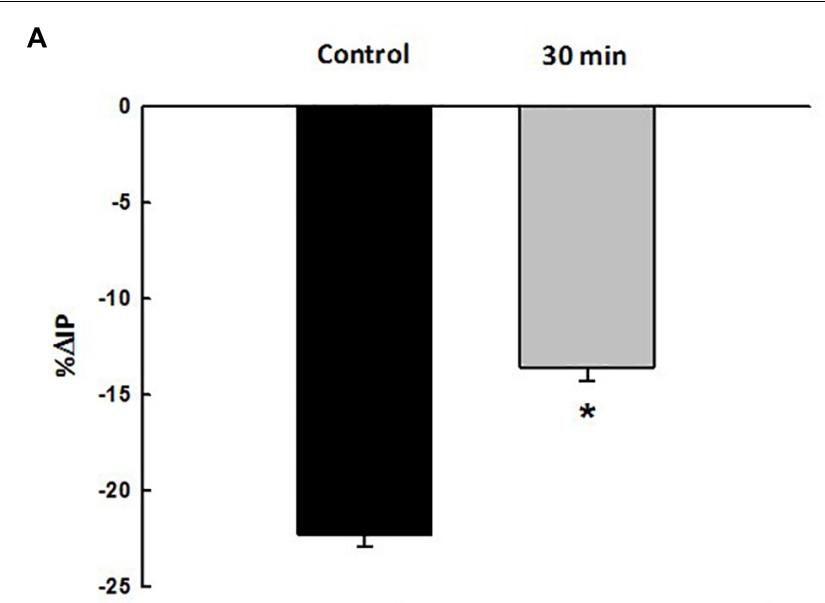

B
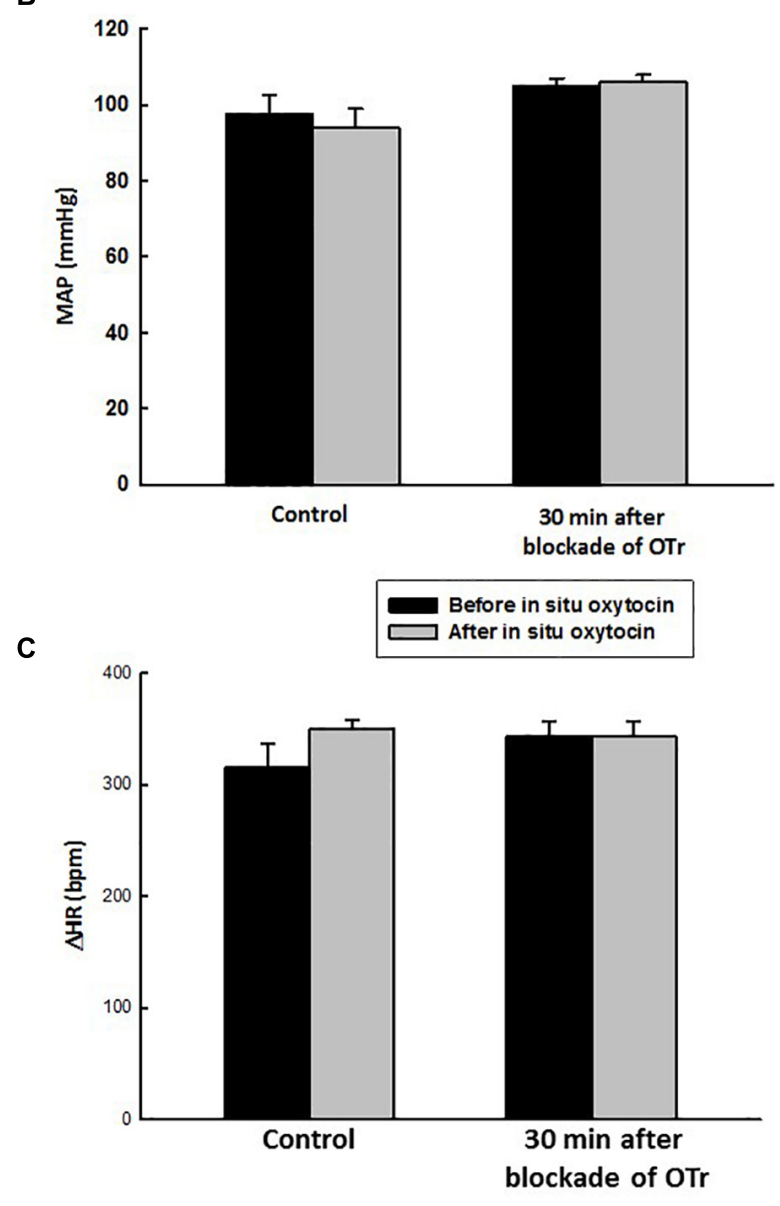

FIGURE 7 | Percent change in intravesical pressure (A, \% $\Delta \mathrm{IP})$ after in situ administration of $0.1 \mathrm{~mL}$ of saline (vehicle) or oxytocin $(0.1 \mathrm{ng} / \mathrm{rat})(\mathrm{N}=7)$ at $35 \mathrm{~min}$ after blockade of oxytocin receptors $(10 \mathrm{ug} / \mathrm{kg}$, i.v.) in intact rats. Mean arterial pressure (B, MAP, $\mathrm{mmHg}$ ) and heart rate $(\mathbf{C}, \mathrm{HR}, \mathrm{bpm})$ at baseline and after in situ administration of $0.1 \mathrm{~mL}$ of saline (vehicle) or oxytocin dose $(0.1$ $\mathrm{ug} / \mathrm{rat} \mathrm{mL}$ ) at $35 \mathrm{~min}$ after blockade of oxytocin receptors (OTr) (10 ug/ $\mathrm{kg}$, i.v.) in sham rats, ${ }^{*} p<0.05$ vs. control $(N=5)$. 


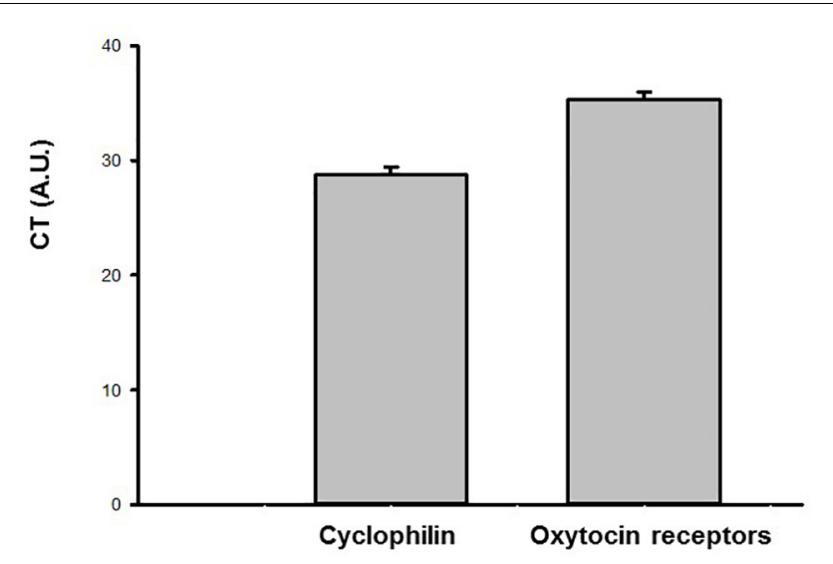

FIGURE 8 | Ct values (arbitrary units, A.U.) obtained by qPCR for the oxytocin (OT) receptor and endogenous housekeeping gene (Cyclophilin A) in the urinary bladder samples of sham animals $(N=6)$.

In the present study, oxytocin effects were also evaluated by in situ administration onto the urinary bladder in order to understand if the responses by intravenous injection were due to direct action on the detrusor muscle or through central mechanisms leading to activation of the autonomic nervous system. Topical (in situ) administration of oxytocin onto the outside of the urinary bladder showed a similar effect compared to the intravenous injection. This finding suggests that oxytocin can diffuse the serosa layer of the bladder and act directly on receptors in detrusor layer when it is topically administrated. Oxytocin evoked a peak drop in IP $\sim 5$ min after topical administration, whereas intravenous injection of oxytocin elicited the peak decrease in IP $\sim 15$ min after starting the infusion. The drop in IP either after intravenous injection or in situ administration of oxytocin lasted for additional $5 \mathrm{~min}$ after achieving the peak response. Those differences in the latency for the onset of fall in IP likely lay in the fact that oxytocin after topical application can achieve the receptors in the bladder faster than after intravenous injection. In the last one, oxytocin is dissolved in the circulation and needs to reach out the bladder in order to bind to the receptors, taking a while in order to do that.

Our findings also demonstrated that intravenous injection of oxytocin receptor antagonist significantly attenuated the drop in IP elicited either by intravenous or in situ oxytocin, suggesting that oxytocin is acting in its receptors localized in the urinary bladder.

While OT is certainly most known to contract smooth muscle (such as the uterus), relaxatory effects are not unheard of. Studies of Duridanova et al. (1997) have shown that the oxytocin-related relaxation may result from the activation of $\mathrm{Ca}^{2+}$-sensitive $\mathrm{K}^{+}$conductivity via activation of IP3-induced release of $\mathrm{Ca}^{2+}$ from the submembrane located in the cisternae of the sarcoplasmic reticulum $\mathrm{Ca}^{2+}$ stores and in turn, this evokes a non-inactivating component of $\mathrm{K}^{+}$channels, hyperpolarizing the cell membrane.
The release of oxytocin in the circulation has been demonstrated in rats during conditioned fear stimuli in a pathway which involves the A2 noradrenergic neurons in the medulla oblongata (Zhu and Onaka, 2002). Furthermore, oxytocin can be released after noxious stimuli mediated by A1 noradrenergic neurons in the medulla (Onaka et al., 2001). Indeed, it is possible that physiologically, the release of oxytocin and its action in the urinary bladder can be important to avoid the micturition or urine loss during stressful conditions as fear and pain. Nevertheless, it is unknown if the amount of oxytocin varies under different stress conditions and also if oxytocin at high concentration could also bind to vasopressin receptors, eliciting a bladder overactivity (Smith et al., 2011; Hattori et al., 2019).

In conclusion, the current findings suggest that (1) intravenous oxytocin decreases IP due to bladder relaxation not dependent on changes in cardiovascular parameters, (2) in situ topically applied oxytocin also decreases IP and has local bladder effect, (3) oxytocin binds directly in receptors located in the urinary bladder and the effect of OT on the bladder does not appear to be affected by the plasma estrogen levels in female rats, as suggested by the absence of change due to ovariectomy.

\section{DATA AVAILABILITY STATEMENT}

The datasets generated for this study are available on request to the corresponding author.

\section{ETHICS STATEMENT}

The animal study was reviewed and approved by the Ethics Committee for Animal experiments [Comissão de Ética no Uso de Animais (CEUA)] at Faculdade de Medicina do ABC (FMABC), Centro Universitário Saúde ABC. Protocol number 007/2011.

\section{AUTHOR CONTRIBUTIONS}

EC, LS, and LA have carried out the functional experiments. EC, IR, JS, RM, and GG were responsible for the qPCR experiments. EC, BA, DV, and PA have worked on data analysis and discussion. MS has designed the experiments, performed the statistical analysis, obtained the research grant, and also have written the manuscript with EC and PA. All the authors equally contributed to development of the manuscript.

\section{FUNDING}

This research was supported by Sao Paulo Research Foundation (FAPESP, Grant \# 2013/04550-5), Nucleo de Estudos Pesquisa e Assessoria a Saude da Faculdade de Medicina do ABC (NEPASFMABC, Grant \# 2009/01), and CAPES for the scholarship to EC. 


\section{REFERENCES}

Andersson, K. E., and Hedlund, P. (2002). Pharmacologic perspective on the physiology of the lower urinary tract. Urology 60(5 Suppl. 1), 13-20. doi: 10.1016/s0090-4295(02)01786-7

Aoki, Y., Brown, H. W., Brubaker, L., Cornu, J. N., Daly, J. O., and Cartwright, R. (2017). Urinary incontinence in women. Nat. Rev. Dis. Primers 3:17042. doi: $10.1038 /$ nrdp. 2017.42

Bakker, E., van Sprundel, M., van der Auwera, J. C., van Gool, J. D., and Wyndaele, J. J. (2002). Voiding habits and wetting in a population of 4,332 Belgian schoolchildren aged between 10 and 14 years. Scand. J. Urol. Nephrol. 36, 354-362. doi: 10.1080/003655902320783863

Bale, T. L., Dorsa, D. M., and Johnston, C. A. (1995). Oxytocin receptor mRNA expression in the ventromedial hypothalamus during the estrous cycle. J. Neurosci. 15, 5058-5064. doi: 10.1523/jneurosci.15-07-05058.1995

Cafarchio, E. M., Auresco, L. C., da Silva, L. A., Rodart, I. F., do Vale, B., de Souza, J. S., et al. (2018). Unravelling the intravenous and in situ vasopressin effects on the urinary bladder in anesthetized female rats: more than one vasopressin receptor subtype involved? Eur. J. Pharmacol. 834, 109-117. doi: 10.1016/j. ejphar.2018.07.024

Cafarchio, E. M., da Silva, L. A., Auresco, L. C., Ogihara, C. A., Almeida, R. L., Giannocco, G., et al. (2016). Cholinergic activation of neurons in the medulla oblongata changes urinary bladder activity by plasma vasopressin release in female rats. Eur. J. Pharmacol. 776, 116-123. doi: 10.1016/j.ejphar.2016.02.043

Chen, S. Y., and Chai, C. Y. (2002). Coexistence of neuron integrating urinary bladder activity and pelvic nerve activity in the same cardiovascular areas of the pontomedulla in Cats. Chin. J. Physiol. 45, 41-50.

Crankshaw, D. (1989). [Arg8] vasopressin-induced contractions of rabbit urinary bladder smooth muscle. Eur. J. Pharmacol. 173, 183-188. doi: 10.1016/00142999(89)90517-7

de Groat, W. C. (1998). Anatomy of the central neural pathways controlling the lower urinary tract. Eur. Urol. 34(Suppl. 1), 2-5. doi: 10.1159/000052265

Deer, R. R., and Stallone, J. N. (2016). Effects of estrogen on cerebrovascular function: age-dependent shifts from beneficial to detrimental in small cerebral arteries of the rat. Am. J. Physiol. 310, H1285-H1294. doi: 10.1152/ ajpheart00645.2015

Dehpour, A. R., Kivaj, G. R. T., Delfan, A., and Shahrokhi, M. (1997). The effects of lithium, indomethacin, and neomycin on vasopressin-induced contractions in rat urinary bladder. Gen. Pharmacol. 28, 777-780. doi: 10.1016/s0306-3623(96) 00305-9

Du Vigneaud, V. (1954). Hormones of the posterior pituitary gland: oxytocin and vasopressin. Harvey Lect. 50:26.

Duridanova, D. B., Nedelcheva, M. D., and Gagov, H. S. (1997). Oxytocin-induced changes in single cell $\mathrm{K}+$ currents and smooth muscle contraction of guinea-pig gastric antrum. Eur. J. Endocrinol. 136, 531-538. doi: 10.1530/eje.0.1360531

Freeman, S. M., and Young, L. J. (2016). Comparative perspectives on oxytocin and vasopressin receptor research in rodents and primates: translational implications. J. Neuroendocrinol. 28:12382. doi: 10.1111/jne.12382

Gutkowska, J., Jankowski, M., Lambert, C., Mukaddam-Daher, S., Zingg, H. H., and McCann, S. M. (2000a). Oxytocin releases atrial natriuretic peptide by combining with oxytocin receptors in the heart. Proc. Natl. Acad. Sci. U.S.A. 94, 11704-11709. doi: 10.1073/pnas.94.21.11704

Gutkowska, J., Jankowski, M., Mukaddam-Daher, S., and McCann, S. M. (2000b). Oxytocin is a cardiovascular hormone. Braz. J. Med. Biol. Res. 33, 625-633. doi: 10.1590/s0100-879x2000000600003

Hashim, H., Malmberg, L., Graugaard-Jensen, C., and Abrams, P. (2009). Desmopressin, as a "designer-drug", in the treatment of overactive bladder syndrome. Neurourol. Urodyn. 28, 40-46. doi: 10.1002/nau.20613

Hattori, T., Sugaya, K., Nishijima, S., Kadekawa, K., Ueda, T., and Yamamoto, H. (2019). Emotional stress facilitates micturition reflex: possible inhibition by an $\alpha 1$-adrenoceptor blocker in the conscious and anesthetized state. Int. Neurourol. J. 23, 100-108. doi: 10.5213/inj.1836284.142

Holmquist, F., Lundin, S., Larsson, B., Hedlund, H., and Andersson, K. E. (1991). Studies on binding sites, contents, and effects of AVP in isolated bladder and urethra from rabbits and humans. Am. J. Physiol. 261(4 Pt 2), 865-874.

Johnson, A. K., and Thunhorst, R. L. (1997). The neuroendocrinology of thirst and salt appetite: visceral sensory signals and mechanisms of central integration. Front. Neuroendocrinol. 18, 292-353. doi: 10.1006/frne.1997.0153

Kajiwara, M., Inoue, K., Usui, A., Kurihara, M., and Usui, T. (2004). The micturition habits and prevalence of daytime urinary incontinence in Japanese primary school children. The micturition habits and prevalence of daytime urinary incontinence in Japanese primary school children. J. Urol. 171, 403-407. doi: 10.1097/01.ju.0000101907.87169.06

Narita, K., and Ichimaru, T. (2014). Rat uterine oxytocin receptor and estrogen receptor alpha and beta mRNA levels are regulated by estrogen through multiple estrogen receptors. J. Reprod. Dev. 60, 55-61. doi: 10.1262/jrd.2012139

Narita, K., Murata, T., and Matsuoka, S. (2016). The ventromedial hypothalamus oxytocin induces locomotor behavior regulated by estrogen. Physiol. Behav. 164(Pt A), 107-112. doi: 10.1016/j.physbeh.2016.05.047

Onaka, T., Yamashita, T., Liu, X., Honda, K., Saito, T., and Yagi, K. (2001). Medullary A1 noradrenergic neurones may mediate oxytocin release after noxious stimuli. Neuroreport 12, 2499-2502. doi: 10.1097/00001756200108080-00042

Pandita, R. K., Nylen, A., and Andersson, K. E. (1998). Oxytocin-induced stimulation and inhibition of bladder activity in normal, conscious ratsinfluence of nitric oxide synthase inhibition. Neuroscience 85, 1113-1119. doi: 10.1016/s0306-4522(97)00651-9

Petty, M. A., Lang, R. E., Unger, T., and Ganten, D. (1985). The cardiovascular effects of oxytocin in conscious male rats. Eur. J. Pharmacol. 112, 203-210. doi: 10.1016/0014-2999(85)90497-2

Romine, M. T., and Anderson, G. F. (1985). Evidence for oxytocin receptors in the urinary bladder of the rabbit. Can. J. Physiol. Pharmacol. 63, 287-291. doi: $10.1139 / \mathrm{y} 85-052$

Ross, C. A., Ruggiero, D. A., Park, D. H., Joh, T. H., Sved, A. F., FernandezPardal, J., et al. (1984). Tonic vasomotor control by the rostral ventrolateral medulla: effect of electrical or chemical stimulation of the area containing C1 adrenaline neurons on arterial pressure, heart rate, and plasma catecholamines and vasopressin. Neurosci. Lett. 4, 474-494. doi: 10.1523/jneurosci.04-0200474.1984

Smith, A. L., Leung, J., Kun, S., Zhang, R., Karagiannides, I., Raz, S., et al. (2011). The effects of acute and chronic psychological stress on bladder function in a rodent model. Urology 78:967. doi: 10.1016/j.urology.2011. 06.041

Steers, W. D. (1998). "Physiology and pharmacology of the bladder and urethra," in Campbell's Urology, 7th Edn, eds P. C. Walsh, A. B. Retik, E. D. Vaughan, and A. J. Wein (Philadelphia: W.B. Saunders), 870-915.

Stern, J. (2015). Neuroendocrine-autonomic integration in the paraventricular nucleus: novel roles for dendritically released neuropeptides. J. Neuroendocrinol. 27, 487-497. doi: 10.1111/jne.12252

Sureshkumar, P., Jones, M., Cumming, R., and Craig, J. (2009). A population based study of 2,856 school-age children with urinary incontinence. J. Urol. 181, $808-815$.

Swanson, L. W., and Sawchenko, P. E. (1980). Paraventricular nucleus: a site for the integration of neuroendocrine and autonomic mechanisms. Neuroendocrinology 31, 410-417. doi: 10.1159/000123111

Zhou, Y., and Forsling, M. L. (2000). Effect of reproductive status on plasma oxytocin concentrations and the renal response to oxytocin in the conscious rat. Exp. Physiol. 85, 73-78. doi: 10.1111/j.1469-445x.2000.01922.x

Zhu, L., and Onaka, T. (2002). Involvement of medullary A2 noradrenergic neurons in the activation of oxytocin neurons after conditioned fear stimuli. Eur. J. Neurosci. 16, 2186-2198. doi: 10.1046/j.1460-9568.2002.02285.x

Zigon, N. J. (2013). Vasopressin and oxytocin in control of the cardiovascular system. Curr. Neuropharmacol. 11, 218-230. doi: $10.2174 / 1570159 \times 11311020008$

Zingg, H. H., Rozen, F., Breton, C., Larcher, A., Neculcea, J., Chu, K., et al. (1995). Gonadal steroid regulation of oxytocin and oxytocin receptor gene expression. Adv. Exp. Med. Biol. 395, 395-404.

Conflict of Interest: The authors declare that the research was conducted in the absence of any commercial or financial relationships that could be construed as a potential conflict of interest.

Copyright (C) 2020 Cafarchio, da Silva, Auresco, Rodart, de Souza, Antonio, Venancio, Maifrino, Maciel, Giannocco, Aronsson and Sato. This is an open-access article distributed under the terms of the Creative Commons Attribution License (CC BY). The use, distribution or reproduction in other forums is permitted, provided the original author(s) and the copyright owner(s) are credited and that the original publication in this journal is cited, in accordance with accepted academic practice. No use, distribution or reproduction is permitted which does not comply with these terms. 